\title{
Activation of liver $X$ receptor (LXR) enhances de novo fatty acid synthesis in bovine mammary epithelial cells
}

\author{
J. W. McFadden ${ }^{1}$ and B. A. Corl ${ }^{2}$ \\ Department of Dairy Science, Virginia Polytechnic Institute and State University, Blacksburg 24061
}

\begin{abstract}
Liver $\mathrm{X}$ receptor (LXR) is a nuclear receptor and a known regulator of lipid synthesis in rodents; however, the role of LXR in the regulation of fatty acid synthesis in bovine mammary epithelial cells has not yet been defined. The objective of the study was to evaluate the effect of LXR activation on the de novo synthesis of fatty acids in bovine mammary epithelial cells (BMEUV). Bovine mammary epithelial cells were treated with T0901317 (T09), an LXR agonist. Treatment of BME-UV with T09 increased the transcription of ATPbinding cassette transporter-G1, an LXR target gene, without modifying LXR $\alpha$ mRNA abundance. Acute and chronic treatment of BME-UV with T09 dramatically increased de novo fatty acid synthesis. Activation of LXR resulted in the upregulation of transcription, translation, and proteolytic cleavage of sterol regulatory element-binding protein-1 (SREBP1), a lipogenic transcription factor expressed in the bovine mammary gland. Additionally, the mRNA abundance of fatty acid synthase, an LXR and SREBP1 target gene, increased in response to LXR activation. Our data indicate that SREBP1 is regulated by LXR activation in BME-UV. Controlling LXR activation may prove useful in regulating milk fat production in lactating dairy cows.
\end{abstract}

Key words: bovine mammary epithelial cell, fat synthesis, liver $\mathrm{X}$ receptor (LXR), sterol regulatory element-binding protein (SREBP)

\section{INTRODUCTION}

Liver X receptors (LXR) are nuclear receptors that regulate the synthesis of lipid and control cholesterol homeostasis upon activation by oxysterols or synthetic agonists (Lehmann et al., 1997; Schultz et al., 2000). Liver X receptor- $\alpha$ and $\operatorname{LXR} \beta$ are 2 known isoforms

Received February 24, 2010.

Accepted June 29, 2010.

${ }^{1}$ Present address: Johns Hopkins University School of Medicine, Department of Neuroscience, 470 Rangos Building, Baltimore, MD 21205.

${ }^{2}$ Corresponding author: bcorl@vt.edu
(Song et al., 1994; Willy et al., 1995), and both regulate the transcription of lipogenic enzymes by binding to DNA in a heterodimeric complex with retinoid X receptor (RXR; Willy et al., 1995). Mice carrying a mutated LXR $\alpha$ gene have decreased expression of acetyl-CoA carboxylase (ACC), fatty acid synthase (FAS), and sterol regulatory element-binding protein-1 (SREBP1), cellular proteins with significant roles in the synthesis of fatty acids (Peet et al., 1998).

Sterol regulatory element-binding protein- 1 is a membrane-bound transcription factor that directly regulates the synthesis and uptake of cholesterol and fatty acids (see review by Brown and Goldstein, 1997). The promoters of the lipogenic enzymes ACC, FAS, and glycerol-3-phosphate acyltransferase (GPAT) all contain a sterol response element (SRE) capable of binding SREBP1 (Lopez et al., 1996; Magana and Osborne, 1996; Ericsson et al., 1997). Interestingly, the promoter of SREBP1c contains a liver X response element (LXRE) for LXR $\alpha$ and LXR $\beta$, suggesting the potential for transcriptional regulation of SREBP1c by LXRs (Yoshikawa et al., 2001).

Sterol regulatory element-binding protein-1 is responsive to LXR activation. In rat hepatoma cells, transcription of SREBP1c was stimulated by oxysterols that activate LXR $\alpha$ and LXR $\beta$ (DeBose-Boyd et al., 2001). Incubation of human preadipocytes with T0901317 (T09), an LXR agonist, increased abundance of ACC, FAS, and SREBP1c mRNA (Darimont et al., 2006). In wild-type mice, activation of LXR by T09 increased relative amounts of hepatic SREBP1, ACC, FAS, and GPAT mRNA, and this effect was markedly reduced in SREBP1c knockout mice, indicating an essential role of SREBP1c in the LXR response (Liang et al., 2002). In addition to LXR indirectly promoting the transcription of ACC and FAS by increasing the expression of SREBP1c, LXR can increase the transcription of ACC and FAS by binding to an LXRE found within the promoter region of these lipogenic genes (Joseph et al., 2002; Talukdar and Hillgartner, 2006). In SREBP1c knockout mice, Liang and coworkers (2002) observed an increase in ACC and FAS mRNA abundance in response to T09, suggesting a direct effect on ACC and FAS mRNA abundance by LXR. 
Sterol regulatory element-binding protein-1 is one of the primary regulators of mammary lipid synthesis as indicated by diet-induced milk fat depression and treatment with conjugated linoleic acid (Harvatine and Bauman, 2006); however, the role of LXR in mammary lipid synthesis is unknown. In dairy cows, expression of $\operatorname{LXR} \alpha$, but not $\mathrm{LXR} \beta$, is increased during lactation compared with nonlactating mammary tissue (Harvatine and Bauman, 2007; Mani et al., 2009). In addition, Farke and coworkers (2008) identified the presence of LXR $\alpha$ in bovine mammary tissue, but did not elucidate its role in lipid metabolism. Therefore, our objective was to evaluate the effect of LXR activation on de novo fatty acid synthesis in bovine mammary epithelial cells.

\section{MATERIALS AND METHODS}

\section{Cell Culture and Treatments}

Chemicals were purchased from Sigma-Aldrich (St. Louis, MO) unless noted otherwise. All experiments utilized bovine mammary epithelial (BME-UV) cells (Zavizion et al., 1996). Cells were seeded on plastic cell culture plates at a density of $5 \times 10^{5}$ cells $/ \mathrm{cm}^{2}$ and cultured at $37^{\circ} \mathrm{C}$ in $5 \% \mathrm{CO}_{2}$. Cells were grown in Dulbecco's modified Eagle's medium (DMEM) with $10 \mathrm{kU} / \mathrm{mL}$ penicillin, $10 \mathrm{mg} / \mathrm{mL}$ streptomycin, and 25 $\mu \mathrm{g} / \mathrm{mL}$ amphotericin B supplemented with $10 \%$ fetal bovine serum. Once cells reached confluence, serum was removed and hormones $(0.1 \mu \mathrm{g} / \mathrm{mL}$ insulin and $1.5 \mu \mathrm{g} /$ $\mathrm{mL}$ prolactin) were added to the basal media. Cells were cultured in basal media with hormones for $24 \mathrm{~h}$ and then treatments were applied.

Cells were treated with T09 $(2 \mu M)$ for 8 (acute) or 24 $\mathrm{h}$ (chronic). In a separate experiment, cells were treated with T09 $(2 \mu M)$ with or without $10 \mu M$ geranylgeranyl pyrophosphate (GGPP) for $24 \mathrm{~h}$. Dimethyl sulfoxide served as control when evaluating the effects of T09 or
GGPP. Cells were treated with $0.4 \%$ dimethyl sulfoxide or less.

\section{Sample Analysis}

De novo fatty acid synthesis was determined by quantifying the incorporation of $\left[1-{ }^{14} \mathrm{C}\right]$-labeled acetate into lipid after 8 or $24 \mathrm{~h}$ of treatment. Activity was calculated and expressed as picomole of acetate incorporated per microgram of DNA. Methods for fatty acid synthesis and DNA quantification were adapted from McFadden and Corl (2009).

Total RNA was extracted from cultured cells using TRI Reagent (Molecular Research Center Inc., Cincinnati, $\mathrm{OH}$ ) according to the manufacturer's instructions. Ribonucleic acid pellets were resuspended in RNase-free water and quantified at $260 \mathrm{~nm}$ using a spectrophotometer. Total RNA (500 ng per reaction) was reverse transcribed into cDNA using the Omniscript reverse transcription kit (Qiagen, Valencia, CA) according to the manufacturer's instructions using oligo(dT) (Roche Applied Science, Indianapolis, IN) as the primer.

Real-time PCR reactions were performed using the Quantitect SYBR Green PCR kit (Qiagen) and an Applied Biosystems 7300 Real-time PCR machine (Applied Biosystems, Foster City, CA). Quantification of gene transcripts for LXR $\alpha$, ATP-binding cassette transporter-G1 (ABCG1), cytochrome P4501A1 (Cyp1A1), SREBP1, insulin-induced gene-1 (INSIG1), insulin-induced gene-2 (INSIG2), and FAS was completed using gene-specific primers. GenBank accession numbers for primers are included in Table 1 . The cycle threshold $(\mathbf{C t})$ values for $\beta$-actin were not statistically different between treatments or sets; therefore, $\beta$-actin was used as the endogenous control gene. Reaction conditions were as follows: 1 cycle at $95^{\circ} \mathrm{C}$ for $10 \mathrm{~min}$ followed by 40 cycles at $95^{\circ} \mathrm{C}$ for $30 \mathrm{~s}, 58^{\circ} \mathrm{C}$ for $30 \mathrm{~s}$, and $72^{\circ} \mathrm{C}$ for $1 \mathrm{~min}$.

Table 1. Summary of genes, primers, and product sizes

\begin{tabular}{|c|c|c|c|c|c|}
\hline $\mathrm{LXR} \alpha$ & TCAACCCCATCTTCGAGTTC & ACGACTACTTTGACCACTCG & Yes & 232 & NM_001014861 \\
\hline Cyp1A1 & CCGACCTCTACAGCTTCACC & CTTGGCCTCCTTGTTCACAT & No & 185 & AB060696 \\
\hline $\mathrm{SREBP}^{2}$ & ATGCCATCGAGAAACGCTAC & CTCTTGGACTCAGACGCCTG & Yes & 180 & NM_214157 \\
\hline INSIG1 & GTCATCGCCACCATCTTCTC & AGTGGAACCTCTCGGTGTGTT & Yes & 115 & XM_589325 \\
\hline INSIG2 & TCCAGTGTGATGCGGTGTGTA & AGTGTGACCGACGTGATAGTT & Yes & 108 & XM_614207 \\
\hline
\end{tabular}

${ }^{1} \mathrm{LXR} \alpha=$ liver $\mathrm{X}$ receptor- $\alpha$; ABCG1 = ATP-binding cassette transporter-G1; Cyp1A1 = cytochrome P4501A1; SREBP1 = sterol regulatory element-binding protein-1; INSIG1 = insulin-induced gene-1; INSIG2 = insulin-induced gene-2; FAS = fatty acid synthase.

${ }^{2}$ Primer pairs do not distinguish between SREBP1a and SREBP1c isoforms. 
For determination of premature and mature SREBP1 (pSREBP1 and mSREBP1, respectively) proteins, BME-UV cells were harvested and processed as described previously by DeBose-Boyd et al. (1999) with the following modifications. Briefly, cells were harvested in media from two 100-mm cell culture dishes and centrifuged at $250 \times g$ for $5 \mathrm{~min}$ at $4^{\circ} \mathrm{C}$. The supernatant was removed and cells were washed with ice-cold PBS and centrifuged at $250 \times g$ for $5 \mathrm{~min}$ at $4^{\circ} \mathrm{C}$. The cell pellet was resuspended in $0.6 \mathrm{~mL}$ of buffer A $(10 \mathrm{mM}$ HEPES-KOH at pH 7.6, $10 \mathrm{mM} \mathrm{KCl,} 1.5 \mathrm{mM} \mathrm{MgCl}_{2}$, $1 \mathrm{~m} M$ sodium EDTA, $250 \mathrm{~m} M$ sucrose, and protease inhibitor cocktail), passed through a 25 -gauge needle 25 times, and centrifuged at $1,000 \times g$ for $5 \mathrm{~min}$ at $4^{\circ} \mathrm{C}$. The resulting pellet was resuspended in $0.1 \mathrm{~mL}$ of buffer B (20 m $M$ HEPES-KOH at $\mathrm{pH} 7.6,2.5 \% \mathrm{vol} / \mathrm{vol}$ glycerol, $0.42 M \mathrm{NaCl}, 1.5 \mathrm{~m} M \mathrm{MgCl} 2,1 \mathrm{~m} M$ sodium EDTA, and protease inhibitor cocktail), rocked at $4{ }^{\circ} \mathrm{C}$ for $1 \mathrm{~h}$, and centrifuged at $100,000 \times g$ for $15 \mathrm{~min}$ at $4^{\circ} \mathrm{C}$. The supernatant from this centrifugation was designated the nuclear extract. The supernatant from the original $1,000 \times g$ spin was used to prepare the membrane fraction by centrifugation at $10,000 \times g$ for $15 \mathrm{~min}$ at $4^{\circ} \mathrm{C}$. The resulting membrane pellets were resuspended in $0.1 \mathrm{~mL}$ of ice-cold lysis buffer $(50 \mathrm{mM}$ Tris $\mathrm{pH} 7.4,0.5 \%$ Triton $\mathrm{X}-100,0.3 \mathrm{M} \mathrm{NaCl}, 2 \mathrm{mM}$ EDTA, and protease inhibitor cocktail).

Nuclear and membrane extracts were assayed for protein concentration using the Bradford assay (Bio-Rad, Hercules, CA) and then diluted to the same protein concentrations with Laemmli sample buffer (Bio-Rad) and heated at $95^{\circ} \mathrm{C}$ for $7 \mathrm{~min}$. Proteins were separated by SDS-PAGE, transferred to polyvinylidene fluoride membranes, blocked with $5 \%$ dried nonfat milk in Tris-buffered saline-Tween, and incubated with antiSREBP-1 primary antibody (sc-13551, Santa Cruz Biotechnology, Santa Cruz, CA). Bound antibodies were detected with horseradish peroxidase-linked secondary antibodies and detected using chemiluminescence (ECL-Plus, Amersham Biosciences, Pittsburgh, PA). Chemiluminescence was measured using a Chemidoc XRS digital imaging system. Luminescence was quantified using Quantity One software (Bio-Rad) and expressed as net intensity (arbitrary units).

\section{Statistical Analysis}

All data were analyzed using the Mixed procedure of SAS (SAS 9.1, SAS Institute Inc., Cary, NC). Abundance of pSREBP1 or mSREBP1 in BME-UV was analyzed according to the model $Y_{\mathrm{ijk}}=\mu+\mathrm{T}_{\mathrm{i}}+\mathrm{S}_{\mathrm{j}}+$ $\varepsilon_{\mathrm{ijk}}$, where $\mathrm{Y}_{\mathrm{ijk}}$ is the individual observation, $\mu$ is the overall mean, $\mathrm{T}_{\mathrm{i}}$ is the fixed effect of treatment $(\mathrm{i}=1$, and 2$), S_{j}$ is the fixed effect of set $(j=1$, and 2$)$, and $\varepsilon_{\mathrm{ijk}}$ is the residual error term. The model $\mathrm{Y}_{\mathrm{ijkl}}=\mu+$ $\mathrm{T}_{\mathrm{i}}+\mathrm{S}_{\mathrm{j}}+(\mathrm{T} \times \mathrm{S})_{\mathrm{ij}}+\mathrm{R}_{(\mathrm{j}) \mathrm{k}}+\varepsilon_{\mathrm{ijk} \mathrm{l}}$ was used to analyze all other data, where $(T \times S)_{i j}$ is the fixed effect of the interaction between treatment and set, $R_{(j) k}$ is the random effect of replicate within set $(\mathrm{k}=1,2$, and 3$)$, and $\varepsilon_{\mathrm{ijkl}}$ is the residual error term. One well represents 1 individual observation. Treatments include the presence of T09 and GGPP. Treatments were performed in triplicate wells per independent experiment unless otherwise noted. One set represents 1 independent experiment and each set differed in cell passage number. Results did not differ across sets and data were pooled. If a significant treatment effect was observed, Tukey's multiple comparison procedure was used to separate treatment means. Real-time PCR data were analyzed using transcript $\mathrm{Ct}$ values normalized with $\beta$-actin as the endogenous control gene $(\Delta \mathrm{Ct})$. For the purpose of presentation, least squares means are illustrated as fold change relative to control using the $2^{-\Delta \Delta \mathrm{Ct}}$ method (Livak and Schmittgen, 2001).

\section{RESULTS AND DISCUSSION}

The function of LXRs in the bovine mammary gland is undefined. In dairy cows, expression of LXR $\alpha$, but not $\operatorname{LXR} \beta$, is increased during lactation compared with nonlactating mammary tissue (Harvatine and Bauman, 2007). To our knowledge, the activation of LXR $\alpha$ in BME-UV has not been investigated before this experiment.

\section{T09 Is an Effective LXR Agonist}

Nuclear receptors such as LXR undergo a conformational change upon ligand binding that promotes their activity. T0901317 is a synthetic, nonsteroidal compound and a highly potent, selective LXR $\alpha$ ligand (Schultz et al., 2000). In addition, T09 increases LXR activity without modifying LXR expression (Houck et al., 2004). In agreement with previously published data, LXR $\alpha$ mRNA abundance was unaffected by acute or chronic treatment with T09 in BME-UV (Figure 1). Moreover, ATP-binding cassette transporter-G1 and Cyp1A1 are known LXR target genes and are upregulated in response to T09 (Dressel et al., 2003; Westerink and Schoonen, 2007). The ATP-binding cassette transporter-G1 has been implicated in the efflux of cholesterol to high-density lipoprotein (Wang et al., 2004). Recently, the presence of ABCG1 was verified in the bovine mammary gland (Farke et al., 2008). In response to acute and chronic treatment with T09, ABCG1 mRNA abundance increased $(P<0.001)$ 11- and 43-fold, respectively (Figure 1). Cytochrome P4501A1 was unresponsive to T09 (Figure 1). Mani 

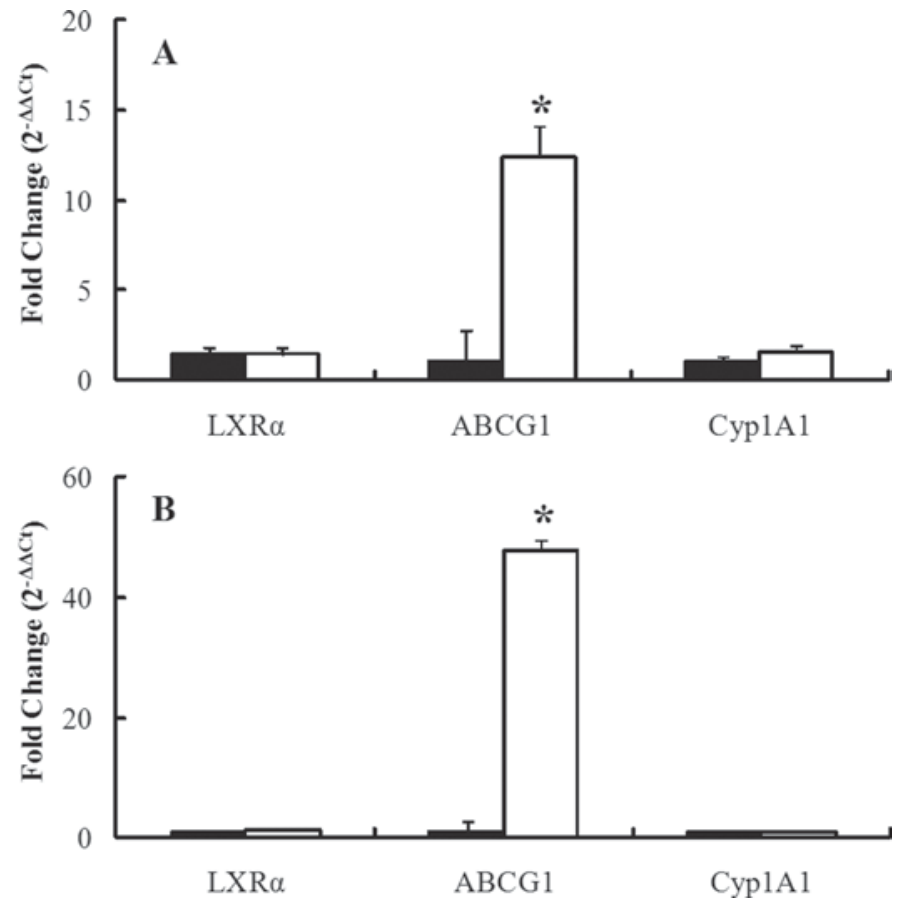

Figure 1. Liver $\mathrm{X}$ receptor (LXR) activation increases target gene abundance without modifying LXR $\alpha$ mRNA abundance. (A) Acute and (B) chronic effects of $2 \mu M$ T0901317 on gene abundance. Genes evaluated were LXR $\alpha$, ATP-binding cassette transporter-G1 (ABCG1), and cytochrome P4501A1 (Cyp1A1). Solid and open bars represent control and T0901317 treatments, respectively. Data are presented as least squares means with 2 independent experiments and 3 replicate wells per experiment. Error bars represent SEM calculated using the $2^{-\Delta \Delta \mathrm{Ct}}$. An asterisk indicates a significant difference in $\Delta \mathrm{Ct}$ from control, $P<0.001$.

and coworkers (2009) compared the expression of lipid transporters and regulators in the mammary glands of dairy cows between the dry period and early lactation. Their results demonstrated a significant increase in LXR $\alpha$ mRNA abundance in conjunction with the onset of lactation. Additionally, they observed a positive correlation between the mRNA abundance of ABCG1 and LXR $\alpha$, suggesting that LXR $\alpha$ regulates ABCG1 in the bovine mammary gland. We conclude that LXR is present in BME-UV mammary epithelial cells and elicits a prototypical response to treatment with T09. In addition, activation of LXR may serve as a potential regulator of cholesterol homeostasis in the bovine mammary gland.

\section{LXR Activation Increases De Novo Fatty Acid Synthesis}

Liver X receptors regulate the synthesis of lipids including cholesterol, bile acids, and fatty acids. Liver X receptor- $\alpha$ is a major sensor of dietary cholesterol and functions as an important transcriptional control point
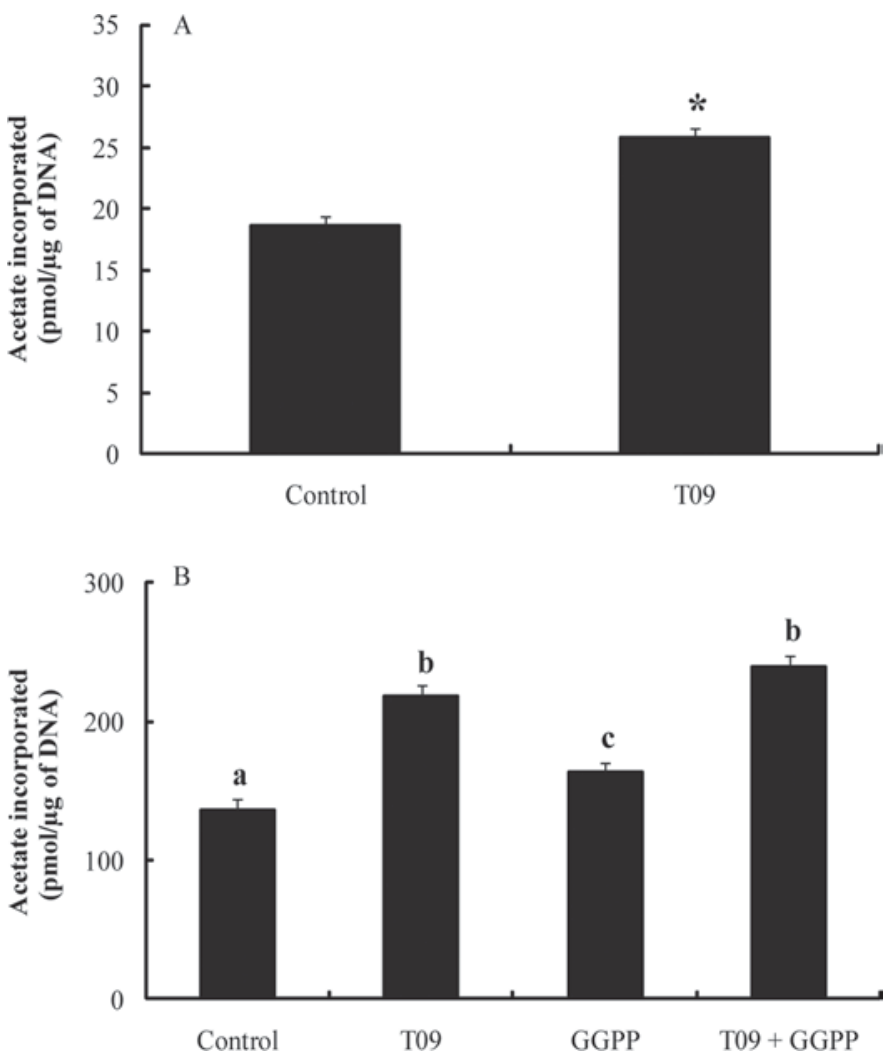

Figure 2. Liver X receptor activation increases de novo fatty acid synthesis. (A) Acute treatment with $2 \mu M$ T0901317 (T09) increased incorporation of radiolabeled acetate into fatty acids in BME-UV bovine mammary epithelial cells; (B) chronic treatment with $2 \mu M$ T09 increased de novo fatty acid synthesis; however, $10 \mu M$ geranylgeranyl pyrophosphate (GGPP) failed to reverse this effect. Control represents the absence of T09 and GGPP. Error bars represent SEM. Treatment differences are signified by an asterisk (A) or differing letters (B), $P$ $<0.001$.

in bile acid synthesis (Peet et al., 1998). The ability of LXR to regulate fatty acid synthesis has also been demonstrated. Peet and coworkers (1998) found that mice carrying a targeted disruption of the LXR $\alpha$ gene had decreased expression of ACC, FAS, stearoyl-CoA desaturase-1, and SREBP1. Furthermore, oral administration of T09 to C57BL/6 mice resulted in the upregulation of lipogenic enzyme expression and increased plasma triacylglycerol levels (Schultz et al., 2000). In the present study, acute and chronic treatment with 2 $\mu M$ T09 increased $(P<0.001)$ de novo fatty acid synthesis in BME-UV by 38 and $60 \%$, respectively (Figure 2 ). Treatment of BME-UV with T09 concentrations greater than $2 \mu M$ resulted in cell death (our unpublished data). Geranylgeranyl pyrophosphate is an LXR antagonist that decreases the transcription of LXR target genes (Gan et al., 2001). Chronic treatment of BME-UV with GGPP failed to reverse the T09-induced increase in de novo fatty acid synthesis (Figure 2B). 

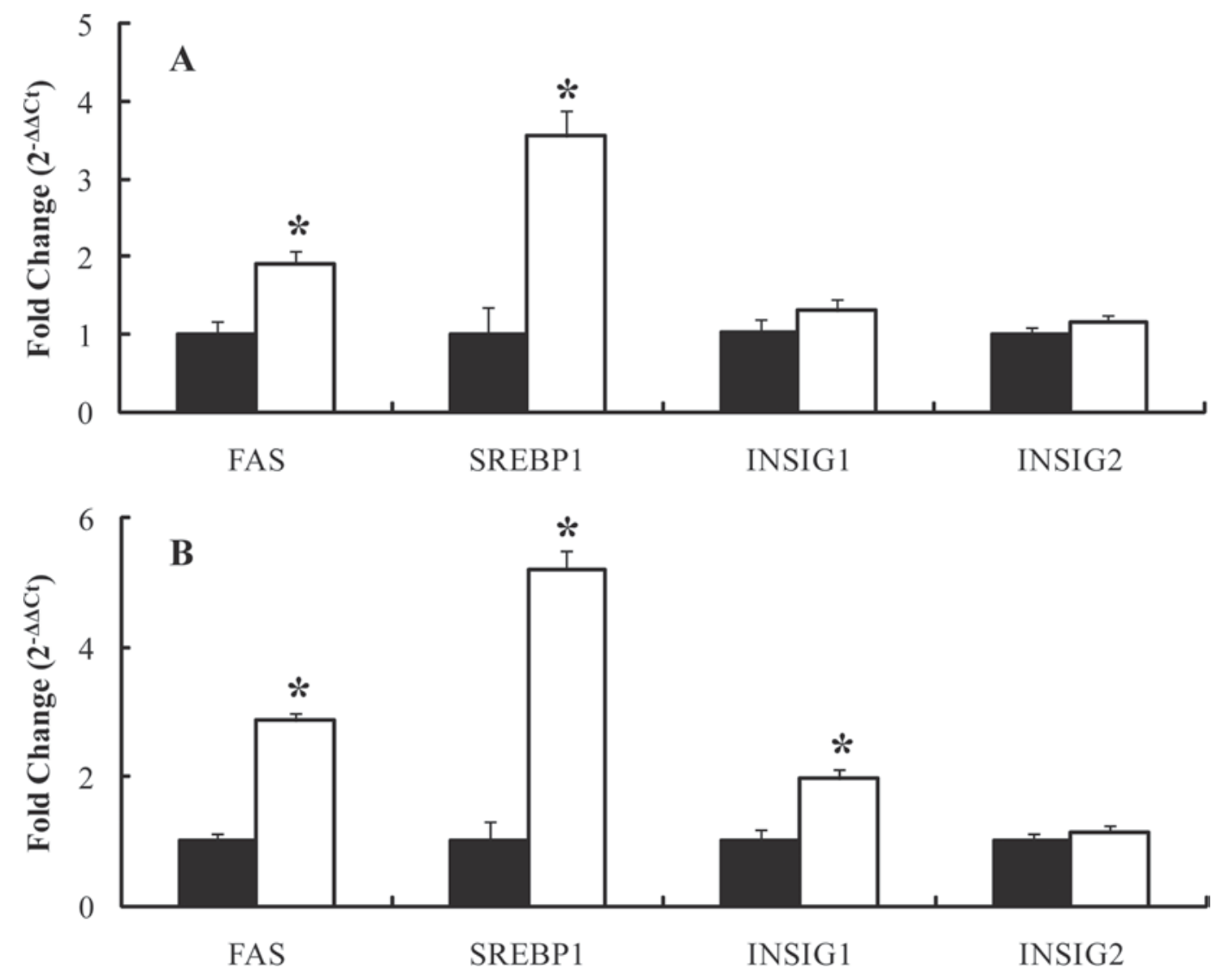

Figure 3. Liver X receptor activation increases lipogenic mRNA abundance. Effect of (A) acute and (B) chronic liver X receptor activation on fatty acid synthase (FAS), sterol regulatory element-binding protein-1 (SREBP1), insulin-induced gene-1 (INSIG1), and insulin-induced gene2 (INSIG2) mRNA abundance. Bovine mammary epithelial cells (BME-UV cells) were treated with or without $2 \mu M$ T0901317 (open and solid bars, respectively). Data are presented as least squares means with 2 independent experiments and 3 replicate wells per experiment. Error bars represent SEM calculated using the $2^{-\Delta \Delta \mathrm{Ct}}$. An asterisk indicates a significant difference in $\Delta \mathrm{Ct}$ from control, $P<0.001$.

In human monocytic leukemia and intestinal epithelial cell lines, Gan and coworkers (2001) demonstrated the ability of GGPP to antagonize LXR. They concluded that GGPP could directly antagonize LXR by reducing the interaction between LXR and steroid receptor coactivator-1, a nuclear coactivator. It is currently not known if steroid receptor coactivator-1 is expressed and functional in the bovine mammary gland. Bovine mammary gland LXR may not depend on steroid receptor coactivator-1 for activation or LXR may interact with a different coactivator. Geranylgeranyl pyrophosphate may be unable to inhibit LXR in BME-UV because of these unknown factors. Regardless of these unknowns, the lipogenic response to T09 was rapid and was sustained over a 24 -h period.

\section{LXR Activation Increases SREBP1 mRNA and Protein Abundance}

Activation of LXR by T09 enhances the expression of SREBP1 (Repa et al., 2000). Repa et al. (2000) concluded that cholesterol-derived oxysterols activate LXR to induce expression of the mouse SREBP1c gene through an LXRE located within its proximal promoter. In addition, the SREBP1a and SREBP2 isoforms were unresponsive to LXR activation by T09 (Schultz et al., 2000; DeBose-Boyd et al., 2001). The expression of SREBP1 has been shown to be significantly upregulated during lactation in mice and cows and is considered the primary regulator of milk fat synthesis (Bionaz and Loor, 2008). In the present study, acute and chronic treatment of BME-UV with T09 increased $(P<0.001)$ the mRNA abundance of SREBP1 by 255 and $416 \%$, respectively (Figure 3 ). We also observed an increase $(P<0.10)$ in protein abundance for pSREBP1 and mSREBP1 in response to 8-h treatment with T09 (Figure 4). This may indicate that LXR is acting globally to increase lipogenesis through SREBP1. Diet-induced milk fat depression is characterized by a reduction in mammary expression of SREBP1 (Harvatine and Bauman, 2006); therefore, activating LXR and increasing SREBP1 protein abundance could reverse the inhibi- 

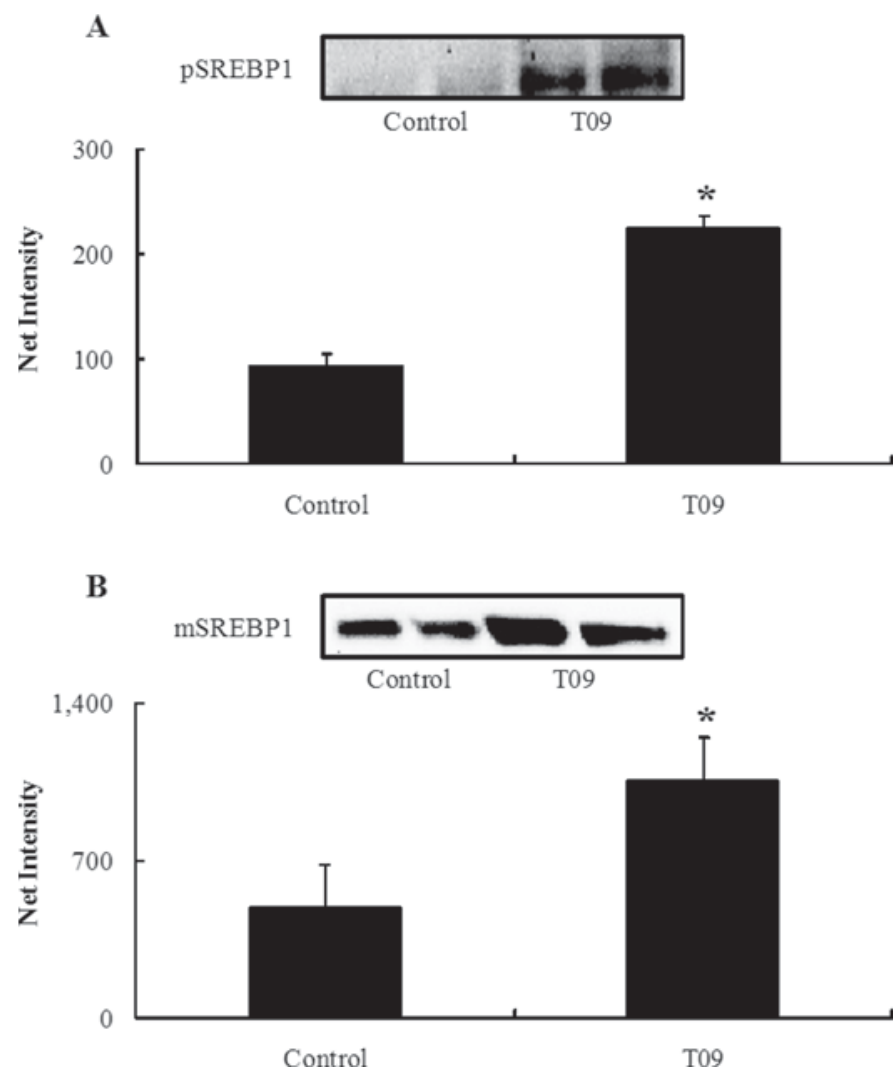

Figure 4. Liver $\mathrm{X}$ receptor activation increase premature and mature sterol regulatory element-binding protein-1 (pSREBP1 and mSREBP1, respectively) protein abundance. Bovine mammary epithelial cells (BME-UV cells) treated with or without $2 \mu M$ T0901317 (T09) for $8 \mathrm{~h}$ increased (A) pSREBP1 and (B) mSREBP1 protein abundance. Data are presented as least squares means with 2 independent experiments and 2 replicate wells per experiment. Error bars represent SEM. An asterisk indicates a significant difference from control (A) $P<0.05$ and (B) $P<0.10$.

tory effect of low-fiber, high-concentrate diets on milk fat synthesis.

Insulin-induced gene-1 and INSIG2 are integral membrane proteins that cause retention of SREBP1 in the endoplasmic reticulum, preventing SREBP1 activation. Interestingly, the INSIG1 promoter can be regulated by transcriptionally active SREBP1 (Kast-Woelbern et al., 2004). Overexpression of INSIG1 in the livers of transgenic mice inhibits SREBP1 processing and reduces insulin-stimulated lipogenesis (Engelking et al., 2004). In the present study, the mRNA abundance of INSIG1 was unaffected by acute treatment with T09 (Figure 3A); however, chronic treatment of BME-UV with T09 increased $(P<0.001)$ the mRNA abundance of INSIG1 (Figure 3B). Chronic treatment with T09 may have lessened the proteolytic cleavage of pSREBP1 by promoting the development of a negative feedback response through increased INSIG1 expression. Therefore, maximum increases in fatty acid synthesis in response to chronic T09 may have been reduced by feedback inhibition. The mRNA abundance of INSIG2 was unaffected by acute or chronic treatment with T09 (Figure 3), indicating that this effect may be unique to the INSIG1 isoform. We conclude that it is possible that INSIG1 retained a portion of pSREBP1 within the endoplasmic reticulum, possibly dampening the ability of T09 to increase de novo lipogenesis over a 24-h period.

\section{LXR Activation Increases FAS mRNA Abundance}

Fatty acid synthase is a known SREBP1 target gene and an essential enzyme in the de novo synthesis of fatty acids (Magana and Osborne, 1996; Harvatine and Bauman, 2006). In human preadipocytes, the mRNA abundance of FAS and SREBP1c is increased in response to T09 (Darimont et al., 2006). In the present study, acute and chronic treatment with T09 increased $(P<0.001)$ FAS mRNA abundance by 89 and $185 \%$, respectively (Figure 3). This may indicate the indirect involvement of SREBP1 because the FAS promoter contains tandem SREBP1c binding sites (Joseph et al., 2002). Alternatively, LXR may act directly by binding to LXR/RXR binding sites found within the FAS promoter (Joseph et al., 2002). Joseph and coworkers (2002) confirmed that maximum induction of FAS requires both LXR and SREBP1c binding to their respective response elements within the promoter region. Therefore, treatment of BME-UV with T09 most likely increased FAS abundance by increasing SREBP1 and LXR binding, resulting in maximum activation. Whether or not SREBP1 and LXR acted in concert or independent of each other remains to be determined. Further examination of the activation of the FAS promoter will be required to resolve this uncertainty. Additionally, bioinformatic examination of the promoters of other lipogenic genes in the bovine genome may reveal LXRE sites that regulate transcription. We conclude that acute and chronic activation of LXR increased de novo fatty acid synthesis in BME-UV. Additionally, we observed an increase in SREBP1 and FAS abundance in response to LXR activation. It remains to be determined whether LXR directly or indirectly regulates FAS abundance.

\section{CONCLUSIONS}

Liver $\mathrm{X}$ receptor regulates the de novo synthesis of fatty acids in BME-UV by promoting the transcription of SREBP1 and FAS. Activation of LXR by T09 may prove to be a useful tool in identifying the relative contributions of LXR $\alpha$ and SREBP1 toward the overall synthesis of fatty acids in the bovine mammary gland. 
Controlling the activation of LXR in the mammary gland of the lactating dairy cow may give producers the ability to modify milk fat production to meet consumer demand.

\section{ACKNOWLEDGMENTS}

This project was supported by National Research Initiative Competitive Grant no. 20093520405358 from the USDA National Institute of Food and Agriculture (Washington, DC).

\section{REFERENCES}

Bionaz, M., and J. J. Loor. 2008. Gene networks driving bovine milk fat synthesis during the lactation cycle. BMC Genomics 9:366.

Brown, M. S., and J. L. Goldstein. 1997. The SREBP pathway: Regulation of cholesterol metabolism by proteolysis of a membranebound transcription factor. Cell 89:331-340.

Darimont, C., O. Avanti, I. Zbinden, P. Leone-Vautravers, R. Mansourian, V. Giusti, and K. Mace. 2006. Liver x receptor preferentially activates de novo lipogenesis in human preadipocytes. Biochimie 88:309-318.

DeBose-Boyd, R. A., M. S. Brown, W. P. Li, A. Nohturfft, J. L. Goldstein, and P. J. Espenshade. 1999. Transport-dependent proteolysis of SREBP: Relocation of site-1 protease from Golgi to ER obviates the need for SREBP transport to Golgi. Cell 99:703-712

DeBose-Boyd, R. A., J. F. Ou, J. L. Goldstein, and M. S. Brown. 2001. Expression of sterol regulatory element-binding protein 1c (SREBP-1c) mRNA in rat hepatoma cells requires endogenous LXR ligands. Proc. Natl. Acad. Sci. USA 98:1477-1482.

Dressel, U., T. L. Allen, J. B. Pippal, P. R. Rohde, P. Lau, and G. E. Muscat. 2003. The peroxisome proliferator-activated receptor $\beta / \delta$ agonist, GW501516, regulates the expression of genes involved in lipid catabolism and energy uncoupling in skeletal muscle cells. Mol. Endocrinol. 17:2477-2493.

Engelking, L. J., H. Kuriyama, R. E. Hammer, J. D. Horton, M. S. Brown, J. L. Goldstein, and G. Liang. 2004. Overexpression of Insig-1 in the livers of transgenic mice inhibits SREBP processing and reduces insulin-stimulated lipogenesis. J. Clin. Invest. 113:1168-1175.

Ericsson, J., S. M. Jackson, J. B. Kim, B. M. Spiegelman, and P. A. Edwards. 1997. Identification of glycerol-3-phosphate acyltransferase as an adipocyte determination and differentiation factor 1and sterol regulatory element-binding protein-responsive gene. J. Biol. Chem. 272:7298-7305.

Farke, C., H. H. Meyer, R. M. Bruckmaier, and C. Albrecht. 2008. Differential expression of $\mathrm{ABC}$ transporters and their regulatory genes during lactation and dry period in bovine mammary tissue. J. Dairy Res. 75:406-414.

Gan, X., R. Kaplan, J. G. Menke, K. MacNaul, Y. Chen, C. P. Sparrow, G. Zhou, S. D. Wright, and T. Q. Cai. 2001. Dual mechanisms of ABCA1 regulation by geranylgeranyl pyrophosphate. J. Biol. Chem. 276:48702-48708.

Harvatine, K. J., and D. E. Bauman. 2006. SREBP1 and thyroid hormone responsive Spot 14 (S14) are involved in the regulation of bovine mammary lipid synthesis during diet-induced milk fat depression and treatment with CLA. J. Nutr. 136:2468-2474.

Harvatine, K. J., and D. E. Bauman. 2007. Expression of PPAR and LXR nuclear hormone receptor families are not modified during milk fat depression induced by diet or treatment with trans-10, cis-12 conjugated linoleic acid (CLA). J. Dairy Sci. 90(Suppl. 1):59. (Abstr.)

Houck, K. A., K. M. Borchert, C. D. Hepler, J. S. Thomas, K. S. Bramlett, L. F. Michael, and T. P. Burris. 2004. T0901317 is a dual LXR/FXR agonist. Mol. Genet. Metab. 83:184-187.

Joseph, S. B., B. A. Laffitte, P. H. Patel, M. A. Watson, K. E. Matsukuma, R. Walczak, J. L. Collins, T. F. Osborne, and P. Tontonoz.
2002. Direct and indirect mechanisms for regulation of fatty acid synthase gene expression by liver X receptors. J. Biol. Chem. 277:11019-11025.

Kast-Woelbern, H. R., S. L. Dana, R. M. Cesario, L. Sun, L. Y. de Grandpre, M. E. Brooks, D. L. Osburn, A. Reifel-Miller, K. Klausing, and M. D. Leibowitz. 2004. Rosiglitazone induction of Insig-1 in white adipose tissue reveals a novel interplay of peroxisome proliferator-activated receptor $\gamma$ and sterol regulatory elementbinding protein in the regulation of adipogenesis. J. Biol. Chem. 279:23908-23915.

Lehmann, J. M., S. A. Kliewer, L. B. Moore, T. A. Smith-Oliver, B. B. Oliver, J. L. Su, S. S. Sundseth, D. A. Winegar, D. E. Blanchard, T. A. Spencer, and T. M. Willson. 1997. Activation of the nuclear receptor LXR by oxysterols defines a new hormone response pathway. J. Biol. Chem. 272:3137-3140.

Liang, G. S., J. Yang, J. D. Horton, R. E. Hammer, J. L. Goldstein, and M. S. Brown. 2002. Diminished hepatic response to fasting/ refeeding and liver $\mathrm{x}$ receptor agonists in mice with selective deficiency of sterol regulatory element-binding protein-1c. J. Biol. Chem. 277:9520-9528.

Livak, K. J., and T. D. Schmittgen. 2001. Analysis of relative gene expression data using real- time quantitative PCR and the $2(-\Delta \Delta \mathrm{c})$ (T) method. Methods 25:402-408.

Lopez, J. M., M. K. Bennett, H. B. Sanchez, J. M. Rosenfeld, and T. F. Osborne. 1996. Sterol regulation of acetyl coenzyme A carboxylase: A mechanism for coordinate control of cellular lipid. Proc. Natl. Acad. Sci. USA 93:1049-1053.

Magana, M. M., and T. F. Osborne. 1996. Two tandem binding sites for sterol regulatory element binding proteins are required for sterol regulation of fatty-acid synthase promoter. J. Biol. Chem. 271:32689-32694.

Mani, O., M. T. Sorensen, K. Sejrsen, R. M. Bruckmaier, and C. Albrecht. 2009. Differential expression and localization of lipid transporters in the bovine mammary gland during the pregnancylactation cycle. J. Dairy Sci. 92:3744-3756.

McFadden, J. W., and B. A. Corl. 2009. Activation of AMP-activated protein kinase (AMPK) inhibits fatty acid synthesis in bovine mammary epithelial cells. Biochem. Biophys. Res. Commun. 390:388-393

Peet, D. J., S. D. Turley, W. Ma, B. A. Janowski, J. M. Lobaccaro, R. E. Hammer, and D. J. Mangelsdorf. 1998. Cholesterol and bile acid metabolism are impaired in mice lacking the nuclear oxysterol receptor LXR $\alpha$. Cell 93:693-704.

Repa, J. J., G. Liang, J. Ou, Y. Bashmakov, J. M. Lobaccaro, I. Shimomura, B. Shan, M. S. Brown, J. L. Goldstein, and D. J. Mangelsdorf. 2000. Regulation of mouse sterol regulatory elementbinding protein-1c gene (SREBP-1c) by oxysterol receptors, LXR $\alpha$ and LXR $\beta$. Genes Dev. 14:2819-2830.

Schultz, J. R., H. Tu, A. Luk, J. J. Repa, J. C. Medina, L. Li, S. Schwendner, S. Wang, M. Thoolen, D. J. Mangelsdorf, K. D. Lustig, and B. Shan. 2000. Role of LXRs in control of lipogenesis. Genes Dev. 14:2831-2838.

Song, C., J. M. Kokontis, R. A. Hiipakka, and S. S. Liao. 1994. Ubiquitous receptor: A receptor that modulates gene activation by retinoic acid and thyroid-hormone receptors. Proc. Natl. Acad. Sci. USA 91:10809-10813.

Talukdar, S., and F. B. Hillgartner. 2006. The mechanism mediating the activation of acetyl-coenzyme A carboxylase- $\alpha$ gene transcription by the liver X receptor agonist T0-901317. J. Lipid Res. $47: 2451-2461$.

Wang, N., D. Lan, W. Chen, F. Matsuura, and A. R. Tall. 2004. ATP-binding cassette transporters G1 and G4 mediate cellular cholesterol efflux to high-density lipoproteins. Proc. Natl. Acad. Sci. USA 101:9774-9779.

Westerink, W. M., and W. G. Schoonen. 2007. Cytochrome P450 enzyme levels in HepG2 cells and cryopreserved primary human hepatocytes and their induction in HepG2 cells. Toxicol. In Vitro 21:1581-1591.

Willy, P. J., K. Umesono, E. S. Ong, R. M. Evans, R. A. Heyman, and D. J. Mangelsdorf. 1995. LXR, a nuclear receptor that defines a distinct retinoid response pathway. Genes Dev. 9:1033-1045. 
Yoshikawa, T., H. Shimano, M. Amemiya-Kudo, N. Yahagi, A. H. Hasty, T. Matsuzaka, K. Okazaki, Y. Tamura, Y. Iizuka, K. Ohashi, J. I. Osuga, K. Harada, T. Gotoda, S. Kimura, S. Ishibashi, and N. Yamada. 2001. Identification of liver $\mathrm{x}$ receptor-retinoid $\mathrm{x}$ receptor as an activator of the sterol regulatory element-binding protein $1 \mathrm{c}$ gene promoter. Mol. Cell. Biol. 21:2991-3000.
Zavizion, B., M. van Duffelen, W. Schaeffer, and I. Politis. 1996. Establishment and characterization of a bovine mammary epithelial cell line with unique properties. In Vitro Cell. Dev. Biol. Anim. $32: 138-148$ 